8.

Historia del pensamiento jurídico 

Revista de Derecho

de la Pontificia Universidad Católica de Valparaíso

XXXI (Valparaíso, Chile, 2 Semestre de 2008)

[pp. 493 - 525]

\title{
DE LA PROPIEDAD A LAS PROPIEDADES. LA EVOLUCIÓN DE LA CONCEPCIÓN LIBERAL DE LA PROPIEDAD
}

[From Property to Properties.

The Evolution of the Liberal Conceptualization of Property]

\author{
Eduardo Cordero Quinzacara* \\ Pontificia Universidad Católica de Valparaíso
}

\section{RESUMEN}

Este trabajo tiene por objeto identificar los elementos nucleares que han conformado la disciplina de la propiedad a partir de las revoluciones liberales, con la finalidad de explicar el sentido y función de este derecho en los ordenamientos jurídicos contemporáneos. Para tal efecto, se desarrollan los fundamentos de la concepción liberal de la propiedad y la formulación de su carácter absoluto, para luego explicar su transformación conceptual como poder funcionalizado, a partir de la juridificación de la "cuestión social" a través de la cláusula de la "función social de la propiedad”, que permite sostener la existencia de una pluralidad de estatutos dominicales frente a la concepción unitaria liberal.

Palabras Clave: Propiedad - Función social de la propiedad - Concepción liberal de la propiedad.

\section{ABSTRACT}

This work attempts to identify the nuclear elements of the discipline of property from the liberal revolutions, in order to explain the sense and function of this right in the contemporary legal systems. For this purpose, the basics for the liberal conceptualization of property and the formulation of its absolute nature are developed, to then explain its conceptual transformation as a functionalized power, from the juridification of the "social question", through the clause of the "social function of property," which allows sustaining the existence of a plurality of property statues before the liberal Unitarian conception .

Keywords: Property - Social function of property - Liberal conception of property.

* Profesor de Derecho administrativo en la Facultad de Derecho de la Pontificia Universidad Católica de Valparaíso. Dirección postal: Pontificia Universidad Católica de Valparaíso, Facultad de Derecho, Avenida Brasil 2950, Valparaíso, Chile. Correo electrónico: eduardo.cordero@ucv.cl 


\section{INTRODUCCIÓN}

El derecho de propiedad siempre ha sido una pieza clave de nuestra cultura y civilización. Su régimen jurídico constituye uno de los elementos arquitectónicos básicos del sistema social, político y económico, así como uno de los núcleos o pilares centrales de los ordenamientos jurídicos occidentales. Es comprensible, por tanto, que se afirme que la propiedad no sería sólo un derecho, sino que "el derecho", pues nuestro universo jurídico es de imposible explicación sin él ${ }^{1}$.

Sin embargo, a su vez, es posible encontrar autores como Grossi que afirmen que "ningún discurso jurídico está quizás tan empapado de bien y de mal, tan sazonado por visiones maniqueas como aquél que se refiere a la relación hombre-bienes. Porque son tan grandes los intereses en juego que inevitablemente las opciones económico-jurídicas vienen defendidas por las corazas no corrosibles de las connotaciones éticas y religiosas"2. Y esto es lo que ha ocurrido con el derecho de propiedad, él que ha adquirido en el curso de la Edad Moderna un "singular arquetipo jurídico" que surge del modelo napoleónico-pandectístico, caracterizado no sólo por la apropiación individual de los bienes, sino por "una apropiación de contenidos particularmente potestativos" de una visión no armónica del mundo, pero exquisitamente antropocéntrica, según una bien individualizada tradición cultural que, exasperando la invitación consignada en los textos sacratísimos de las antiguas tablas religiosas a dominar la tierra y a ejercitar el dominio sobre las cosas y sobre las criaturas inferiores, legitimaba y sacralizaba la insensibilidad y el desprecio por la realidad no humana".

En razón de lo expuesto, uno de los primeros problemas que plantea el estudio del derecho de propiedad es que se trata de un asunto demasiado

\footnotetext{
${ }^{1}$ Cfr. López y López, Ángel, El derecho de propiedad. Una relectio, en Anuario de Derecho Civil 51 (1998) 4, p. 1639.

${ }^{2}$ Grossi, Paolo, La propiedad y las propiedades. Un análisis histórico (traducción de Ángel López y López, Madrid, Civitas, 1992), p. 11.

${ }^{3}$ Ibíd., p. 32.

${ }^{4}$ Ibíd., p. 33. Según este autor "de estos cimientos especulativos nace aquella visión individualista y potestativa de propiedad que hemos acostumbrado llamar la "propiedad moderna”, un producto histórico que, por haber devenido estandarte y conquista de una clase inteligentísima ha sido inteligentemente camuflado como una verdad redescubierta y que cuando los juristas, tardíamente, con los análisis revolucionarios y post revolucionarios en Francia, con los pandectísticos en Alemania, traducen, con el auxilio de instrumental técnico romano, las intuiciones filosóficopolíticas en reglas de derecho y las sistematizan, de respetable consideración teórica se ha deformado en concepto y valor" (pp. 33-34).
} 
multiforme, que exige buscar un método lo suficientemente apropiado para comprender las líneas esenciales, sin que esto conlleve a una reducción cuyos resultados sean escasamente útiles. Además, todo intento por tratar de condensar y sistematizar lo que se ha dicho en torno al derecho de propiedad es una empresa desmesurada y, quizás, hasta imposible para cualquier persona. En tal sentido, nada más acertadas son las palabras de Mariano Peset cuando afirmaba que: "[...] a la propiedad, en su conjunto, sólo se le puede dedicar un ensayo o la vida entera. Y aún dudo que sea suficiente..."

Es evidente que sería un esfuerzo vano, e incluso estulto, tratar de dirigir esta investigación al descubrimiento de algo nuevo sobre un tema de las características de la propiedad. Tampoco resulta conveniente tratar abarcar in totum todos los problemas o cuestiones que sobre este derecho se han debatido. Lo que pretendemos en este trabajo es identificar los elementos nucleares que han conformado la disciplina de la propiedad a partir de las revoluciones liberales, lo cual permite explicar su sentido y función en los ordenamientos jurídicos contemporáneos. A esto dedicaremos las siguientes páginas.

\section{LA CONCEPCIÓN LIBERAL DE LA PROPIEDAD Y SU PROCLAMADO "CARÁCTER ABSOLUTO”}

El modelo de derecho de propiedad seguido en la Europa continental y que reproducen los pueblos americanos, fue el impuesto por el triunfo de la Revolución francesa de 1789 y que significó la asunción del poder por parte de la burguesía y el establecimiento de las bases políticas, económicas y sociales que permitieron configurar la propiedad como un "derecho subjetivo fundamentado en la naturaleza de la persona humana".

Este hecho histórico, que marcará todo el siglo XIX y se proyectará en el siglo XX bajo una profunda revisión, encuentra su causa en el denominado individualismo jurídico, que es el resultado de tres movimientos confluentes: i) el iusnaturalismo racionalista de los siglos XVI y XVII; ii) el movimiento e influencia de la visión económica por parte de los fisiócratas; y iii) las construcciones científicas realizadas por grandes juristas franceses de los siglos XVII y XVIII, en donde destacan Domat, Pothier y Portalis ${ }^{6}$.

${ }^{5}$ Peset, Mariano, Dos ensayos sobre la Historia de la propiedad de la tierra (2a edición, Madrid, Revista de Derecho privado, 1988), p. 15.

${ }^{6}$ Sobre el individualismo moderno y el concepto de propiedad seguimos en este apartado a Villey, Michel, Notas sobre el concepto de propiedad, en Revista de Derecho Público 35-36 (Santiago, 1984), pp. 67-81. 
El iusnaturalismo racionalista se encuentra relacionado con el más amplio movimiento intelectual y político de la Ilustración, que domina el pensamiento europeo del siglo XVII. Este movimiento adopta distintas formas en Inglaterra, Francia y Alemania, pero el elemento o tronco común está constituido por una actitud intelectual de crítica racional del orden social y jurídico de la época, propugnando su reforma en función de la idea de progreso. Crea una nueva metafísica del Derecho utilizando para ello la experiencia de su historicidad y los materiales del Corpus iuris civilis, considerado como ratio scripta, para la formulación de un sistema de Derecho privado fundado racionalmente, lo que conduce a un planteamiento abstracto y atemporal del mismo ${ }^{7}$.

A la luz de este sistema, el hombre aparece como un ser libre por naturaleza y titular de un conjunto de derechos inherentes a su condición, lo que son inalienables e imprescriptibles. La sociedad civil es la forma que adoptan los hombres para proteger sus derechos, los que pueden ser limitados o restringidos sólo en la medida que sea necesario para cumplir este fin.

Las consecuencias de estos postulados en el ámbito del Derecho se

${ }^{7}$ Las doctrinas iusnaturalistas presentan también notables diferencias en sus resultados, como consecuencia de los diversos supuestos ideológicos en el ámbito de la teoría de la organización social, lo que deriva, a su vez, de una diversa concepción acerca del Derecho y de la cuestión fundamental de la interpretación de la idea iusnaturalista de los derechos innatos de la persona. En el plano de la organización política-social se enfrentan las doctrinas a favor del sistema parlamentario (Althusio) y del absolutismo político (Hobbes). En el campo estrictamente jurídico se desarrolla la creencia en una comunidad universal jurídicamente ordenada y la idea de un orden ético de validez general (Grocio), de lo cual se derivó un conjunto de derechos civiles y políticos entendidos como patrimonio jurídico propio de la persona individual $y$, por tanto, como límite de la potestad normativa y fundamento de la legitimidad de la organización jurídico-social. El pensamiento iusnaturalista adquiere un matiz distinto en la cultura germánica, en donde se adopta en las ideas de HobBes en el plano político (absolutismo monárquico) y se orienta en el derecho privado hacia una actitud científica-especulativa, alejándose del empirismo racionalista de Grocio. En este ámbito, aportó una renovación constructiva en el plano conceptual y en el de la ordenación general del Derecho (Pufendorf, Wolff), preparando las bases para la futura unificación del Derecho privado alemán, sobre todo por imprimir una actitud formalista en el pensamiento jurídico, alejado de la dimensión práctica y problemática del ius commune. Véase Fernández BarreIro, A., La tradición romanistica en la cultura jurídica europea (Madrid, Ramón Areces, 1992), pp. 93 ss.; WESENBERG, Gerhard - Wesener, Gunter, Historia del Derecho privado moderno en Alemania y en Europa (traducción de la $4^{\mathrm{a}}$ edición alemana por José Javier de los Mozos Touya, Valladolid, Lex Nova, 1998), pp. 221 ss.; Hattenhauer, Hans, Conceptos fundamentales del Derecho civil. Introducción histórico-dogmática (traducción de Gonzalo Hernández, Barcelona, Ariel, 1987), pp. 111 ss. 
producen a través de la articulación de un conjunto de instrumentos jurídicos que se estructuran sobre la base de los siguientes pilares: el derecho subjetivo (en donde se comprende la libertad individual y el derecho de propiedad), la autonomía de la voluntad, el contrato y la personalidad reconocida a cada individualidad.

El derecho de propiedad es concebido en función de un sujeto abstracto, formalmente igual, siempre idéntico, que dentro del supuesto de hecho de la norma aparece bajo la denominación del anónimo "el que" o "quien" al que se atribuyen las consecuencias jurídicas previstas en las proposiciones normativas codificadas. La "lógica del sujeto" en los códigos decimonónicos integran a la propiedad dentro de un sistema de derechos subjetivos a partir de la irreal figura del "abstracto sujeto propietario".

El derecho subjetivo es un poder que se atribuye a una voluntad para imponerse a una o varias voluntades, cuando quiere una cosa que no está prohibida por la ley. Con esta noción se construye a su vez una concepción subjetiva del ordenamiento jurídico, el que aparece como unidad o constelación de derechos (poderes) subjetivos de todos los sujetos de Derecho (personas privadas y del Estado). Por eso, no es de extrañar que la propiedad sea definida como una especie dentro del género derecho subjetivo, es decir, es un atributo de la persona; es una "facultad" o "poder" que tiene un individuo sobre una cosa, siendo, será además el corolario de libertad o el instrumento para su ejercicio, por eso los grandes idealistas alemanes (Kant, Fichte y Hegel) describían la propiedad como la "esfera de acción libre”, realización exterior de la libertad del individuo?.

${ }^{8}$ LÓPEZ y López, cit. (n. 1), pp. 1.643-1.644.

${ }^{9}$ Esta conjunción de la libertad del individuo con el derecho de propiedad ya estaba presente en la obra de John Locke y se remonta a los comienzos de la filosofía moderna (Gerson, Driedo, Occam y también Duns Scotto). Cfr. Villey, cit. (n. 6), p.68. La identificación que se hace entre libertad y propiedad, presente en todas las corrientes individualistas de la Edad Moderna, ya estaba plenamente definida en las construcciones teológicas de los autores de la Segunda Escolástica. La libertad coincide con la propiedad que una persona tiene sobre sí mismo y de sus acciones, la existencia como sujeto libre consiste en una serie de comportamientos dominativos, en suma, en la propiedad que yo tengo de mí mismo. Como corolario, esta propiedad, este dominium sui, se traduce inmediatamente en la propiedad sobre las cosas corporales externas, en el dominium rerum. Véase Lobato GÓMEZ, J., Miguel, Propiedad privada del suelo y derecho a edificar (Madrid, Montecorvo, 1989), pp. 47-48. Por su parte Grossi, Paolo, Le situazioni reali nell esperienza giuridica medievale (Padova, Cedam, 1968), pp. 148-149 dice que: "la libertad del individuo es el presupuesto ineliminable de todo dominium, pero es el dominium el aspecto dinámico mismo de la libertad, es la libertad en acción dentro de su más típico mecanismo protector: es, si queremos, la libertad misma en su realización posesiva de la naturaleza”. Lo expuesto aparece de manifiesto en las definiciones de dominio que ofrece este mo- 
El iusnaturalismo cultivó con detenimiento la noción de propiedad, con el fin de conducirla a su mayor plenitud, para desgajarla en primer lugar de las cargas feudales y para exaltarla después como un poder independiente no sólo respecto de los particulares sino que también respecto del Estado. Con esta finalidad fueron desarrolladas las doctrinas que hablaban de "fuentes naturales de la propiedad" y de "modos originarios de adquisición" 10 .

Paradigma y modelo de este derecho es la Declaración de los Derechos del Hombre y del Ciudadano de 16 de agosto de 1789 y el Code Civil de 1804. En el primero de estos cuerpos normativos se reconoce al derecho de propiedad como un derecho natural del hombre, sagrado e inviolable, de acuerdo a lo prescrito en sus artículos 2: "Le but de toute association politique est la conservation des droits naturels et imprescriptibles de l'homme. Ces droits sont la liberté, la propriété, la sûreté et la résistance à l'oppression"; y 17: "La propriété étant un droit inviolable et sacré, nul ne peut en être privé, si ce n'est lorsque la nécessité publique légalement constaté, l'exige évidemment, et sous la condition d'une juste et préalable indemnitê".

En el Code Civil la propiedad se va a consolidar como un derecho subjetivo, que tiene las características de ser absoluto, exclusivo y perpetuo, según la opinión generalmente compartida por los primeros comentaristas $^{11}$. Tal es el contenido de su artículo 544: "La propriété est le droit de

vimiento, como la de Soto, De iustitia et iure, lib. IV, cuest. 1a, art. 1, (f. 79v): "est propia cuiusque facultas e ius rem quamlibet, quam in suum ipsius commodum usurpare potest quocumque usu lege permisso"; o la de VITORIA In secundum secundae. De Iustitia, ad. Cuest. 57 a , art. 1, nota 29, p. 82. "facultas ad utendum re pro arbitrio suo". Más referencias se pueden consultar en la obra de LOBATO GOMEZ cit. ibid, pp. 48-49.

${ }^{10}$ Para que la propiedad no estuviera sujeta a los peligros del poder público los iusnaturalistas modernos "echan manos a todo tipo de mitos: mito de la primera ocupación, o del derecho del primer ocupante", muy utilizada por Grocio y otros teóricos del racionalismo jurídico. Los moralistas hicieron su aporte fundándola en un precepto bíblico o de la moral estoica que prohíbe el robo; "si me está prohibido tocar la posesión de otro, no cabe sino concluir que él tiene derecho sobre la cosa que ha ocupado". Hume propondrá más tarde la explicación psicológica de la conversión natural de la situación del poseedor en propiedad. En torno a LOCKE se desarrolla la doctrina de la adquisición de la propiedad por el trabajo, que tomaron los fisiócratas y que los economistas le agregarán la apología de los beneficios, cuyas consecuencias son atacadas por MARX, quien dirá "el Derecho de obligaciones y el principio de libertad contractual propician la explotación, mientras que el Derecho de cosas y la obligatoriedad de sus tipos aseguran el botín”. Wolff y Kant justifican la propiedad como una condición necesaria para la perfección de la naturaleza del individuo o de su libertad moral. Cfr. ViLley, cit. (n. 6), p.69. Todos llegan en definitiva a la misma conclusión: la propiedad es un derecho natural del hombre.

${ }^{11}$ Cuando se utiliza el adjetivo absoluto se hace referencia a que su titular tiene 
jouir et disposer des choses de la manière la plus absolue, pourvu qu'on n'en fasse pas un usage prohibé par les lois ou par les règlements"12.

El Code Civil pone una especial atención en las cuestiones vinculadas a la propiedad inmueble o del suelo, lo que hace no solamente por la importancia económica que tiene en aquel momento histórico, sino también con la finalidad de insistir en su plan o política inmediata, que es la de ratificar la abolición definitiva de cualquier derecho feudal sobre la tierra y legitimar las transferencias de propiedad que se habían producido entre los años 1789 y 1804.

La forma y características que adopta el derecho de propiedad en las fuentes francesas es el resultado de la asunción del modelo liberal-burgués, el que necesitaba de una propiedad libre de cargas, es decir, despojada de los esquemas germánicos propios del mundo feudal. Con este importante proceso de desvinculación se unifica el instituto de la propiedad y se atribuye la plenitud de su disposición a su titular, con lo que se busca poner freno al poder que ejercían durante el Antiguo Régimen los monarcas y los nobles ${ }^{13}$.

La propiedad liberal transforma a su titular en un soberano respecto de los bienes, ya que queda entregada a su libre voluntad la determinación de los usos que se le darán, como el destino económico a que pueden ser aplicados. No tiene respecto de ellas ninguna obligación que cumplir, ya que está plenamente facultado para no hacer uso de ellas, dejarlas estériles, improductivas e incluso destruirlas. Esto justifica en todo su alcance el adagio: "Á l'État la souveraineté, au citoyen la propriéte" 14 .

La consagración del absolutismo propietario expresado en la frase "de

un poder ilimitado sobre la cosa (plena in re potesta) y se expresa en todas las posibilidades de hacer (ius utendi, ius fruendi, ius abutendi) que se pueden concebir, tanto material como jurídicamente. Su carácter de exclusivo permite sostener que sólo su titular puede aprovechar y disponer del objeto de su propiedad, por lo que tiene la facultad de impedir que otras personas gocen de él sin su venia o autorización. Por último, su carácter perpetuo significa que el derecho de propiedad dura tanto cuanto dure la cosa sobre la cual recae, y la circunstancia de no darle ningún uso no hace que este derecho se extinga, salvo empero la posibilidad que un tercero pueda usucapirla, pero en este caso estamos ante un supuesto que es distinto a la mera desidia o inactividad de su titular.

${ }^{12} \mathrm{El}$ destacado es nuestro.

${ }^{13}$ Lo que se pretendía era crear un poder absoluto (propiedad) que tuviera la capacidad de hacer contrapeso y limitar el otro poder que detentaba el soberano. Véase RoDotà, Stefano, El terrible derecho. Estudios sobre la propiedad privada (traducción de Luis Díez-Picazo, Madrid, Civitas, 1986), p.101.

${ }^{14}$ Baudry-Lacantinerie, Gabriel - Cheveau, M., Traité théorique et pratique de Droit civil: Des biens (3a edición, Paris, Sirey, 1905), p. 124. 
la manière la plus absolue" del artículo 544 del Code Civil daba a entender que el poder del propietario no estaba sujeto a limitaciones, y así fue interpretado por los miembros de la Escuela de la Exégesis en sus primeros comentarios, como consecuencia de un exagerado dogmatismo ${ }^{15}$. Sin embargo, la expresión tiene un carácter más retórico que jurídico, lo que se deduce por la función trascendental que en el contexto histórico cumple el artículo 544, ya que en su redacción se quiere dejar de manifiesto el término de una etapa (el feudalismo) y el comienzo de una nueva producto de la revolución. Tal expresión es fruto de la euforia y el entusiasmo a consecuencia del radical cambio que se está produciendo por el triunfo de la revolución y el final del Antiguo Régimen.

La misma conclusión se deduce de la propia redacción del precepto, el que utiliza el adjetivo absoluta en su forma superlativa, es decir, la más absoluta o de la manera más absoluta, lo que es claramente innecesario y sólo se entiende por razones retóricas, ya que una interpretación literal no se correspondería con la realidad, en cuanto no da lugar a matices o gradaciones: la propiedad es absoluta o es relativa, no hay términos medios ${ }^{16}$.

Por lo demás, la ausencia de límites dominicales resulta un imposible dentro de la vida en sociedad, ya que ella misma demanda la imposición de reglas y de límites para que se garantice una armónica convivencia entre sus miembros. La sociedad no puede tolerar, ni ha tolerado nunca, tal configuración de la propiedad. Y tratándose de este derecho -como lo expresa Rudolf von Ihering-, la idea de la propiedad no puede conllevar algo que esté en oposición con la idea de sociedad ${ }^{17}$.

De los propios antecedentes del Code Civil se pueden extraer estas conclusiones. El mismo Robespierre afirmó que la propiedad no podía ser establecida con un carácter más absoluto que la propia libertad y postu-

${ }^{15}$ Bonnecase, Julien, L'École de l'Exégèse en Droit civil: Les traits distinctifs de sa doctrine et de ses méthodes d'après la profession de foi de ses plus illustres représentants (2a edición, París, De Boccard, 1924), p. 230, dirá que: “[...] así impregnados de individualismo, privados de iniciativa, servidores de la ley, los exégetas olvidan el alcance social del derecho de propiedad", lo que hacen en un proceso totalmente alejado de la realidad, como lo dice VIDAL, Michel, La propriété dans l'École de l'Exégèse, en EL MISMO, Itinerari moderni della proprietà (Milano, Giuffrè, 1978), I, p. 39: "nutriéndose de deducciones de textos y combinaciones entre ellos, sin lazos con la realidad histórica o realidad social, sin contacto estrecho con los hechos [...]".

${ }^{16}$ En el mismo sentido Grossi, cit. (n. 2), pp. 124-125; PeSET, cit. (n. 5), p. 150; y De los Mozos, José Luis, Voz Propiedad, en Nueva Enciclopedia Jurídica Seix (Barcelona, 1993), XX, y EL MISMO, El derecho de propiedad: crisis y retorno a la tradición jurídica (Madrid, Revista de Derecho privado, 1993), p. 101.

${ }^{17}$ IHERING, Rudolf von, Der Zweck im Recht (Leizpig, Greg Olms, 1970). Hay traducción al español: El fin del Derecho (Buenos Aires, Heliasta, 1978), pp. 252 ss. 
laba su limitación para respetar y permitir el ejercicio de los derechos de propiedad ajenos ${ }^{18}$, idea compartida por Portalis, para quien era necesario que las leyes puedan dirigir las acciones relativas al uso de los bienes. Debe haber libertad con las leyes, no contra las leyes ${ }^{19}$.

Este es el plan seguido en el Code Civil. El artículo 544 reconoce en primer lugar la libertad del propietario en el goce y disposición de las cosas que le pertenecen, pero inmediatamente acota esta libertad subordinando la facultad de usar las cosas al pleno respeto de las prohibiciones que se puedan establecer por ley o reglamento.

En todo caso, debemos tener presente que bajo este modelo de derecho de propiedad no es posible definir con claridad sus contornos. Su conceptualización es tan abierta y expansiva que hace muy difícil, cuando no imposible, poder distinguir entre el ejercicio de las facultades que derivan de la propiedad y del ejercicio de la libertad inherente a toda persona, especialmente en el ámbito económico. Por tal razón los comentaristas no encuentran otro marco o límite del derecho de propiedad que el contenido en las ya mencionadas "leyes o reglamentos" (códigos posteriores sólo harán referencia a las "leyes"), que es, por lo demás, el mismo marco que se establece para el ejercicio del derecho de libertad. El propietario no puede salirse de este marco y el Estado a su vez sólo puede afectar por esta vía el contenido del derecho de propiedad en la menor medida posible y de forma excepcional, prohibiendo determinados usos o imponiendo determinadas restricciones con el objeto de garantizar el orden público, es decir, ejerciendo las modestas funciones que le atribuyen los reglamentos de policía, que buscan ante todo mantener un mínimo orden del statu quo propietario.

Estas determinaciones constituyen "limitaciones externas", compuesta la más de las veces por deberes de carácter negativo. El mismo sentido tendrá la expropiación por razones de pública utilidad o las llamadas servidumbres legales. Todas estas figuras son en general restricciones que impone el legislador al poder absoluto u omnímodo del propietario.

La técnica utilizada es la de concebir un derecho lo más amplio y ab-

${ }^{18}$ Robespierre hizo está propuesta en el discurso de la Convención, pronunciado el 3 de abril de 1793. Véase Rodotà, Stefano, Poteri dei privati e disciplina della proprietà, en EL MISMO, Diritto privato nella società moderna (Bologna, Zanichelli, 1982), pp. 360; y RoDotà, Stefano, El terrible derecho. Estudios sobre propiedad privada (traducción de Luis Díez-Picazo, Madrid, Civitas, 1986), pp.93-94.

${ }^{19}$ Portalis, Jean Etienne Marie, L'âme universelle de la législation, en FENET, Pierre-Antoine y otros, Naissance du Code civil: la raison du législateur: travaux préparatoires du Code civil. An VIII-an XII - 1800-1804 (Paris, Flammarion, 1989), p. 276. 
soluto posible -cuyo sentido original está en la naturaleza humana, que es su fuente- $\mathrm{y}$ dejar a posteriori su configuración al legislador, quien le dará la forma que garantice el ejercicio de todos los derechos de propiedad, sin que alguno impida el ejercicio de otros. Por eso no es posible definir el derecho de propiedad sino que en su forma original, la que no se identifica con lo que en la realidad existe ${ }^{20}$. Además, acorde con la concepción liberal, las limitaciones son entendidas como deberes negativos de "no hacer" establecidos en razón del interés privado, es decir, se ocupan de resolver los conflictos interindividuales, desentendiéndose del interés social de la comunidad ${ }^{21}$.

En conclusión, el modelo ideológico propietario que inspira a los códigos de filiación napoleónica lleva a la construcción de un concepto de propiedad que toma como punto de apoyo al sujeto titular antes que al objeto del derecho. En este concepto son indiferentes las cualidades y accidentes del bien, pues lo que interesa son las facultades o poderes del propietario que se conciben bajo una categoría unitaria caracterizada por una indefinición genérica de tales poderes ( $u t i$, frui, abuti), paradigmas de la utilización económica "soberana". Por tal razón, estos paradigmas están vacíos en su contenido prescriptivo y se mueven en el ámbito de la definición ${ }^{22}$. Así también, ha sido acertada la afirmación de que este modelo

${ }^{20}$ Con posterioridad en Alemania Antón Menger (1841-1906) dará cuenta de esta situación diciendo: "La verdad es que estas restricciones de la propiedad privada encuentran expresión únicamente en manuales, y al margen de los compendios de Derecho civil [...] pero ¿̇no sería ya hora de derribar de una vez por todas esa débil pared e incluir en las definiciones del Código civil la lamentable situación del propietario actual?". Citado por Hattengauer, cit. (n. 7), p. 121.

${ }^{21}$ Véase Colina Garea, Rafael, La función social de la propiedad privada en la Constitución Española de 1978 (Zaragoza, Bosch, 1997), pp.94-97..

${ }^{22}$ En este sentido, véase LÓPEZ y LÓPEZ, cit. (n. 1), p. 1.644 y, especialmente, pp. 1665-1668, señalando al respecto que “[...] la generalidad de la configuración de los poderes del propietario, sólo concretable a través de las normas que fijan sus límites, se añade en la definición codificada que dichos límites también están señalados de modo genérico, per relationem a lo que las leyes establezcan: y hemos visto que en el pensamiento del Código, estas "leyes" (sea cual sea su naturaleza) están fuera de él. [...]. En este sentido, la conclusión sobre el no valor prescriptivo, sino puramente definitorio del artículo 348 del Código civil, debe ser mantenido. [...]. las definiciones de propiedad de los Códigos liberales expresan, en un cierto modo, un valor permanente (históricamente se entiende, no hay concepto o institución jurídica alguna que viva en la trascendencia), y por ello el modelo funciona como paradigma abstracto, al margen de su sustancia normativa, estando disponible para ser rellenado por los más variados contenidos concretos, operados por la lógica de las leyes especiales, aun las que respondan a principios propietarios fuera del arco liberal, incluso cuando son dictados por la Constitución del Estado social”. 
de propiedad es absolutamente lógico, aporético e irreal. Absolutamente lógico porque parte de la perspectiva de un sujeto libre, igual y soberano, él que es inescindible e indivisible, y la propiedad no es más que una extrinsicación de su yo en las cosas del mundo exterior, de forma tal que dicho poder no puede ser sino unitario. Es absolutamente aporético porque es inviable desde un punto de vista racional sostener que dicho poder se pueda fraccionar en un conjunto de facultades de contenido indefinido y genérico, como son los iura fruendi, utendi abutendi y disponendi, para decir posteriormente que reunidas configuran una plena in re potestas. Por último, es absolutamente irreal, porque no es posible sostener un poder tan pleno e ilimitado, cuyo contenido efectivo es extraordinariamente variable, lejos del carácter unitario que de él se profesa ${ }^{23}$.

En definitiva, la Constitución liberal y el Código Civil formaron un par funcional armónico, de lo cual deriva la idea del "valor cuasiconstitucional" del segundo, al que quedaban confiadas las estructuras jurídicas básicas de la posición del individuo en la sociedad.

\section{LA PROPIEDAD COMO UN PODER FUNCIONAL Y SU TRANSFORMACIÓN DOGMÁTICA}

La segunda mitad del siglo XIX va a significar un cambio fundamental en las estructuras sociales y económicas de los países. Tras el proceso de industrialización la forma de vida en la ciudad va a experimentar un cambio substancial, tornándose más compleja respecto de lo que ya ocurría en el ámbito rural. Se produce un proceso de migración a las urbes, con la consiguiente concentración de masas de población en reducidos espacios, y aumentan los conflictos de intereses derivados del ejercicio del derecho de propiedad. La mayor cercanía material de las personas con sus bienes, especialmente con su predio o solar, hace que su comportamiento repercuta en la esfera de intereses de los propietarios colindantes, lo cual genera un aumento cuantitativo de los límites que se impone al ejercicio del derecho de propiedad no sólo por ratio privata, sino también por ratio publica, es decir, por razones de convivencia social.

El régimen del derecho de propiedad no se limita a resolver los conflictos de intereses que puedan surgir entre propietarios. Ahora el conflicto de intereses es de mayor entidad, ya que éste se plantea entre el interés particular del propietario y el interés social de la colectividad.

La función del legislador también cambia, porque éste ya no se restringe a acción de limitación posterior y como mero árbitro entre los conflictos

${ }^{23}$ Cfr. López y López, cit. (n. 1), pp. 1.644-1.645. 
de los particulares, sino que debe configurar el régimen el derecho de propiedad por razones de interés general o público, dándole un sentido funcional dentro del ordenamiento jurídico.

Desde una "lógica nomológica", en esta época destaca la posición que asumen las leyes especiales, existentes antes del Código unas veces, otras posteriores al mismo, pero que originalmente fueron concebidas como excepciones y fragmentaciones del sistema codificado unitario, pero que adquieren con las grandes crisis derivadas de la Primera Guerra Mundial y las revoluciones coetáneas una especial densidad, tanto cuantitativa (por su número, hasta llegar a ser la parte más abultada del ordenamiento jurídico). como cualitativamente (pierden su carácter jurídico excepcional, pues dejan de ser una "legislación de coyuntura" y se transforma en normas habituales y permanentes). De esta manera, las Leyes especiales contribuyeron a crear una nueva dimensión o statu quo social del Derecho en un camino o dirección que no dejaba posibilidad alguna de retorno. Como afirma López y López: "El Código, en muchos aspectos, pertenecía a un mundo periclitado, y nada abonaba su permanencia como regla general operativa que impidiera la entrada en el mundo del Derecho "normal" de las otrora Leyes “especiales" (en el sentido de "excepcionales"), y por consiguiente su inasequibilidad a la analogía y su anclaje en la interpretación restrictiva, como principio hermenéutico propio"24.

Desde la "lógica del sujeto", el abstracto sujeto propietario es confrontado con seres reales, que padecen una condición socialmente menesterosa, cuyo centro de atención surge a partir del sistema político (democracia representativa), económico (evolución del capitalismo maduro que tiene como centro la empresa en lugar de la propiedad), y social (concentración urbana, luchas de clases e ideas socialistas y solidaristas). Surge una nueva cultura jurídica que da un paso sustancial en las aspiraciones de igualdad, pues no se queda en la mera declaración formal que proclama a todos los hombres iguales en derechos y deberes desde su nacimiento, sino que mira a la generación de condiciones efectivas de promoción social y de satisfacción de necesidades mínimas vitales. Así se rompe, desde el punto de vista del sujeto, con el carácter absolutamente irreal del modelo de propiedad liberal, que se formula a partir de la inescindiblidad e indivisibilidad del sujeto un concepto unitario de propiedad, siendo que en la realidad su contenido es extremadamente variable, no unitario, no siempre igual, como tampoco lo es el sujeto que proyecta su poder sobre las cosas.

Por último, desde la "lógica de las cosas", en palabras de Grossi, "aquí había germinado la intuición elemental de que era hora de mirar a la

${ }^{24}$ LÓPEZ y LÓPEZ, cit. (n. 1), p. 1.642. 
relación entre el hombre y las cosas, no desde la altura del sujeto, antes bien poniéndose al nivel de las cosas y observando desde abajo aquella relación, sin preconceptos individualistas y con una disponibilidad total para leer las cosas sin gafas deformadoras. Y las cosas habían revelado que eran estructuras no genéricas sino específicas, con órdenes específicos y diversificados que requieren diversas y particulares construcciones jurídicas, si estas últimas quieren ser adecuadas y no mortificantes" ${ }^{25}$. Esto ha dado lugar a lo que se ha denominado "pluralidad de propiedades", sobre la que hemos de volver con un mayor detenimiento a lo largo de este trabajo.

\section{De la "cuestión social" a la "función social" de la propiedad.}

La sintonía entre la Constitución "liberal” y el Código Civil se comienza a resquebrajar a partir de la denominada "cuestión social" que alteraría sustancialmente la faz de las Constituciones de los Estados europeos, que comenzaban a reflejar un conjunto de valores solidaristas y comunitarios que estaban significativamente ajenos al constitucionalismo clásico que había inspirado y nutrido ideológicamente a los códigos civiles. Este cambio de rumbo repercute con particular intensidad en el terreno del derecho de propiedad, cuando se inserta en su interior, junto a aquel poder idealmente omnipotente del propietario, la idea de deber ("Eigentum verpflichtet").

Los códigos civiles eran depositarios de una amplia idea de libertad como fundamento de la sociedad occidental actual y sin la cual no podríamos vivir, pero al mismo tiempo eran fuente generadora de desigualdades que no eran posibles de aceptar desde el plano ético y moral. Desde los socialistas utópicos (Saint Simon, Fourier, Owen, Proudhon, Cabet, Blanc), pasando por las ideas marxista y el socialismo científico (Marx, Engels), el pensamiento social cristiano (a partir de León XIII y su encíclica Rerum novarum), e incluso en el pensamiento corporativo nacionalsocialista $y$ fascista (aunque desde una ideología totalitaria que niega al individuo consideración ética de persona, y rechaza su propia esencia, como es la de ser sujeto de derecho), se alzan las voces con planteamientos que deseaban una corrección del orden social, en donde el Derecho civil estaba totalmente ajeno a las clases no poseedoras y al mundo del trabajo. Así, en los últimos años del siglo XIX y las primeras décadas del siglo XX, marcan el fin de lo que se ha llamado la belle époque jurídica ${ }^{26}$.

Esto marca el acta de nacimiento de un concepto que reconoce muchos padres legítimos (cristianismo social, socialdemocracia, sociologismo

\footnotetext{
${ }^{25}$ Grossi, cit. (n. 2), p. 21.

${ }^{26}$ Cfr. López y López, cit. (n. 1), p. 1.650.
} 
funcionalista, pensamiento corporativo) y que ha tenido una larga y dispar fortuna: la función social de la propiedad.

Los excesos del individualismo y la crítica desde el plano de la ética o la moral se tradujeron en el plano jurídico en un conjunto de críticas y en una revisión de la tradicional categoría de la propiedad liberal, con el objeto de orientar el poder del propietario al interés de toda la colectividad y no servir únicamente a su interés individual. Así aparecen los primeros escritos de autores como Augusto Comte ${ }^{27}$, Émile Lavelaye ${ }^{28}$, Francisco Giner de los Ríos ${ }^{29}$, Menger $^{30}$, Ihering ${ }^{31}$, Otto von Gierke ${ }^{32}$ y, especial-

${ }^{27}$ Comte, Auguste. Système de politique positive: ou traité de sociologie instituant la religion de l'humanité (Paris, 1890-1895). Este autor afirmaba que: “En todo estado normal de la humanidad, todo ciudadano, cualquiera que sea, constituye realmente un funcionario público, cuyas atribuciones, más o menos definidas, determinan a la vez obligaciones y pretensiones. Este principio universal debe ciertamente extenderse hasta la propiedad, en la que el positivismo ve, sobre todo, una indispensable función social destinada a formar y a administrar los capitales con los cuales cada generación prepara los trabajos de la siguiente. Sabiamente concebida, esta apreciación normal ennoblece su posesión, sin restringir su justa libertad y hasta haciéndola más respetable” [ibíd., (1892, I, p. 156]. COMTe ejerció una influencia decisiva en el pensamiento de Duguit, como lo demuestra la cita sin reservas que hace de su obra.

${ }^{28}$ LAVELEYE, Émile Louis Victor de, De la propriété et de ses formes primitives (Paris, G. Baillière et cie., 1874). Según Grossi, cit. (n. 2), p. 88 esta obra no tiene nada que compartir con tantos volúmenes y ensayos sobre el tema que constelan la literatura jurídica del siglo XX (sobre todo la escuela de la exégesis), siempre apologéticos, siempre fuertemente ideologizados, y siempre carentes de base especulativa y cultural. El libro de Laveleye es de otra clase. Teóricamente no muy sólido, sin veleidades especulativas, no muy docto ni basado en sólidos fundamentos eruditos, revela los límites indudables del autor, que es una personalidad modesta, pero también sus virtudes, consistentes en una gran capacidad intuitiva y en una sensibilidad polivalente. Este es un libro crítico hacia las estructuras capitalistas pero sustancialmente conservador del orden constituido, recibe la ironía o el despreciativo silencio de los marxistas y los ataques demoledores de la cultura oficial.

${ }^{29}$ Dentro de esta materia destacan dos obras de GINER DE LOS Ríos, Francisco, Bases para la teoría de la propiedad (tesis doctoral, Madrid, 1867); y El MISMO, Resumen de filosofía del Derecho (Madrid, Victoriano Suárez, 1898), dos volúmenes. En esta obra expresa que: "El más grave y trascendental de cuantos errores imperan aquí todavía es la de considerar el derecho de propiedad como una mera facultad muda, subjetiva, arbitraria, sin obligaciones correspondientes” [II, p. 433].

${ }^{30}$ Menger, Anton, Über die socialen Aufgaben der Rechtswissenschaft (Wien u. Leipzig, W. Braumüller, 1895).

${ }^{31}$ IHERING, cit. (n. 17), quien llegó a afirmar que: "No es necesario ser profeta para prever que la concepción social del derecho privado sustituirá poco a poco a la concepción individualista” [p. 256].

${ }^{32}$ Gierke, Otto, Die soziale Aufgabe des Privatrechts (Berlín, Springer, 1889). 
mente, de León Duguit ${ }^{33}$.

Un buen ejemplo de este cambio se puede ver en la obra de Gabriel Baudry-Lacantinèrie, quien expresaba en las primeras ediciones de su Précis de droit civil que el propietario "[...] puede legítimamente realizar sobre la cosa actos aunque no tenga ningún interés confesable en realizarlos [...]" y si, al realizarlos causa un daño a otro "[...] no es responsable, porque no hace más que usar su derecho" ${ }^{34}$. Sin embargo, esta fórmula desaparece a partir de la $11^{\circ}$ edición de 1912, y en su lugar queda la declaración que ya venía formulando con la colaboración de Chauvea en su obra Des Biens: "A pesar de su carácter absoluto, la propiedad debe también estar circunscrita a límites racionales [...] El mismo artículo 544 se ocupa de anunciar la existencia de restricciones a las cuales el derecho de propiedad es susceptible de estar sometido. Intereses de orden superior, de orden social, de orden general o público, imponen a veces que se doblegue un poco el absolutismo del derecho de propiedad, que se prohíba a los propietarios ciertos actos de ejercicio, incluso que se les obligue a hacer alguna cosa, a cumplir diversas obligaciones, por el solo hecho de ser detentadores de bienes colocados bajo ciertas condiciones. El legislador, bajo la única reserva del respeto a la constitución y a los principios del derecho público, es libre de determinar la extensión del sacrificio que la propiedad debe sufrir en interés general" 35 .

${ }^{33}$ Véase Duguit, León, Las transformaciones del Derecho público y privado (traducción de A. Posada, R. Jaen y C. Posada, Buenos Aires, Heliasta, 1975); Las transformaciones generales del Derecho privado desde el Código de Napoleón (traducción de Carlos Posada, Valparaíso, Edeval, 1987); Traité de Droit constitutionnel (Paris, E. de Boccard, 1927), I, pp. 445 ss.; y Le droit social, le droit individuel et la transformation de l'État: conférences faites á l'École des Hautes Études Sociales (3a edición, Paris, F. Alcan, 1922).

${ }^{34}$ La primera edición es de 1882-1884 [BAUDRY-LACANTINÈRIE, Gabriel, Précis de Droit civil (3 vol., Paris, Larose, 1882-1884), tres volúmenes]. La cita la hemos tomado de la $10^{\mathrm{a}}$ ed. [BAudrY-LaCantinèrie, Gabriel, Précis de Droit civil (10ª edición, Paris, Larose), I, 1908, núm. 1.296, p. 726].

${ }^{35}$ Baudry-Lacantinèrie, cit. (n. 34), pp. 150-160. El destacado es nuestro. Por su parte DE VITA, Anna, La proprietà nell'esperienza giuridica contemporanea: analisi comparativa del Diritto francese (Milano, Giuffrè, 1969), pp. 49-50 señala que las transformaciones que el sentido de la norma del Code civil sufre en el Derecho francés pueden reducirse a los siguientes factores: i) el creciente número de límites que de hecho o de derecho han restringido notablemente el ámbito de ejercicio de las prerrogativas del propietario; ii) los efectos de la doctrina del relativismo jurídico, y de la ideología anti-individualista en el plano conceptual; y iii) a la obra de la jurisprudencia en la construcción del principio del abuso del derecho, que se inserta en la amplia problemática de los límites y de la función social de la propiedad, y a la protección siempre mayor concedida a derechos e intereses del arrendatario y, en particular, del arrendatario comerciante. 
No obstante, esta propuesta sigue bajo la estela metodológica liberal, pues a pesar de la intensidad de estas "restricciones" o "sacrificios", se siguen comprendiendo bajo la idea de limitaciones al poder del propietario que no encuentran su raíz en dicho poder, sino aliunde, es decir, externamente, como sucede con la soberanía política. En sí mismas, tales limitaciones son ajenas a la potestad del sujeto propietario, y vienen residenciadas en la necesidad de considerar jurídicamente existentes a los otros, sean los otros propietarios, sea el otro soberano actuante sobre las cosas, el Estado, en función de prerrogativas que le son propias.

Sin embargo, a pesar de la excesiva extensión de los cánones jurídicoliberales, el objeto interpretado había variado considerablemente. La relación institucional de especificación entre Código Civil y leyes especiales va desapareciendo, porque la especialidad de las leyes no consiste ya en su carácter especificante, sino que se centra en su dimensión sectorial. Con ello las restricciones a los poderes reconocidos tradicionalmente al propietario por el ordenamiento jurídico aumentan y se consolidan progresivamente en materias de aguas, minas, caza y pesca, utilización de montes, policía rural y urbana, etc., para intentar conseguir una satisfactoria protección de los intereses públicos y una adecuada realización de los mismos sin recurrir a los medios que venían siendo usados para este fin: la expropiación forzosa y la constitución de servidumbres legales en interés público ${ }^{36}$. De esta forma, el proceso legislativo iniciado a fines del siglo XIX da cuenta del "momento natural" de la propiedad privada y, en consecuencia, su fundamento es reconducido al "momento civil", esto es, a la ley positiva ${ }^{37}$.

Esto significó un cambio de grandes repercusiones en el plano epistemológico, cuyo centro de atención se radica en las normas que configuran el derecho de propiedad, antes que en los límites de un derecho natural y preexistente. Estas nuevas "gafas metodológicas" colocarán al derecho de propiedad en una nueva posición frente a la ley. La Ley puede establecer límites ("Begrenzungen") o limitaciones ("Beschränkungen") al derecho de propiedad, esto es, configurar o determinar el contenido normal del derecho de propiedad (límites) o establecer restricciones que operan circunstanciadamente sobre el contenido definido de la propiedad (limitaciones). Este será el aporte de la Escuela dogmática alemana a partir de Otto von Gierke, la que tendrá trascendencia en la doctrina alemana posterior, así como en los demás países del entorno europeo, especialmente en Italia y España ${ }^{38}$.

\footnotetext{
${ }^{36}$ Lobato GÓmEZ, cit. (n. 9), pp. 86-87.

${ }^{37}$ Ibíd.

${ }^{38}$ Dentro de las obras alemanas se pueden mencionar a GIERKE, Otto von, Sachenrecht, en Deutsches Privatrecht (Leipzig, Duncker \& Humblot, 1905), II.; WolfF,
} 
Esta concepción "nomológica" o normativa del derecho de propiedad se entrecruza con la función social que se le ha asignado a partir de un ordenamiento jurídico atestado de "leyes especiales" de evidente contenido social y que se engastan en el contenido natural del derecho de propiedad. Este cambio de perspectiva llega a su formulación más extrema con el iuspublicista francés León Duguit, quien en el año 1905 pronunció un discurso al Congrès National de la Propriété Batie, con la cual comienza a tomar cuerpo la teoría de la "función social"39.

Duguit trató de los profundos cambios experimentados por el sistema de Derecho civil, que se había construido en la Europa del siglo XX sobre las bases del modelo francés surgido de la revolución (Declaración de los Derechos del hombre y del ciudadano de 1789 y el Código Civil de 1804). Después de explicar las bases de este sistema individualista o subjetivista del Derecho (libertad individual, derecho subjetivo, autonomía de la voluntad, la personalidad y la capacidad jurídica de los sujetos de Derecho,

Martín, Reichsverfassung und Eigentum, en Festgabe der Berlienr Juristischen Fakultät für Wilhelm Kahl, zum Doktorjubiläum am 19. April 1923 (Tübingen, Verlag von J.C.B. Mohr, 1923); WIEACKER, Franz, Wandlungen der Eigentumsverfassung (Hamburg, Hanseat, 1935); HolsteIn, Günther, Die Lehre von der öffentlich-rechtlichen Eigentumsbeschränkung (Berlin, Liebmann, 1921); Hamann, Andreas. Deutsches Wirtschaftsverfassungsrecht (Neuwied, Luchterhand, 1958); HubER, Ernst Rudolf, Wirtschaftsverwaltungsrecht (2a edición, Tübingen, Mohr, 1953), II; MaUnZ, Theodor, Deutsches Staatsrecht (10ª edición, München, Berlin, Beck, 1961); BetTerman, Karl August, Neumann, Franz L. - Nipperdey, Hans Carl, Die Grundrechte: Handbuch der Theorie und Praxis der Grundrechte (Berlin, Duncker \& Humblot, 1967); ReInHARDT, Rudolf - SCHEuner, Ulrich, Verfassungsschutz des Eigentums (Tübingen, Mohr, 1954). Dentro de la influencia italiana destacan las obras de Pugliatti, Salvatore, La proprietà nel nuovo Diritto (Milano, Giuffrè, 1954); y de Coco, Giovanni Silvio, Crisi ed evoluzione nel diritto di proprietà (Milano, Giuffrè, 1965). Una síntesis de esta recepción y de su aplicación al Derecho español es el trabajo de MARTín MAteo, Ramón, El estatuto de la propiedad inmobiliaria, en Revista de Administración Pública 52 (1967), pp. 101-150. También se pueden ver los trabajos de PAREjO ALFONSO, Luciano, La garantía del derecho de propiedad y la ordenación urbanistica en el Derecho alemán (I), en Revista Española de Derecho Administrativo 17 (1978), pp. 245-272; La garantía del derecho de propiedad y la ordenación urbanistica en el Derecho alemán (II), en Revista Española de Derecho Administrativo 19 (1978), pp. 541-570; y La garantía del derecho de propiedad y la ordenación urbanistica en el Derecho alemán (III), en Revista Española de Derecho Administrativo 20 (1979), pp. 33-56.

${ }^{39}$ Resulta curioso que Duguit pronunciara este discurso en defensa de los propietarios de edificios en consideración al servicio público que cumplían, advirtiendo que si el legislador imponía cargas demasiado gravosas sobre los propietarios de las construcciones, impediría que estos cumplieran su "función social". Cfr. LEVY, Jean Philippe, Histoire de la propriété (Paris, Presses Universitaires de France, 1972), p. 104. 
la inviolabilidad de la propiedad, etc.), Duguit señala que la consecuencia más grave de esta construcción se manifiesta en el derecho de propiedad, ya que su titular tiene no sólo el derecho de usar, gozar y disponer de la cosa, sino que también el derecho de no usar, no gozar y no disponer, es decir, de hacer un ejercicio antisocial o, por lo menos, asocial del mismo. Sin embargo, la institución de la propiedad privada no es ajena a los cambios económicos y sociales, los que exigen una mayor solidaridad o interdependencia social. Además, en la ciencia jurídica comienza a experimentar la crisis de dos instituciones fundamentales del sistema liberal: el derecho subjetivo y la autonomía de la voluntad. Para las corrientes realistas y positivistas ambas nociones tenían un carácter de orden metafísico antes que estrictamente jurídico.

El modelo de propiedad liberal comienza su degradación, ya que se asienta bajo la forma de derecho subjetivo centrada en la sola utilidad individual del propietario. La reconversión de la función de este derecho bajo la idea de deber permite legitimar el uso, goce y disfrute de los bienes por su sentido de beneficio o utilidad social. Se produce la "socialización" de la propiedad privada, lo que marca el paso y la superación de la "propiedad especulación" -institución propia del individualismo jurídico- a la "propiedad-función", lo que va a significar la diversificación o la existencia de una pluralidad de propiedades, en consideración a las distintas funciones sociales que puedan obtenerse de los bienes, rompiendo con el modelo civil codificado de la propiedad. Por eso Duguit afirmará que: “[...] sobre el hecho de la interdependencia social y sobre la división del trabajo, induzco naturalmente las dos proposiciones siguientes: $1^{\circ} \mathrm{El}$ propietario tiene el deber, y por tanto el poder, de emplear la cosa que posee en la satisfacción de las necesidades individuales, y especialmente de las suyas propias [...] $2^{\circ}$ El propietario tiene el deber, y por consiguiente el poder, de emplear su cosa en la satisfacción de necesidades comunes, de una colectividad nacional entera o de colectividades secundarias [...] Ante todo, el propietario tiene el deber y el poder de emplear la riqueza que posee en la satisfacción de sus necesidades individuales. Pero, bien entendido, que no se trata más que de los actos que corresponden al ejercicio de la libertad individual, tal como anteriormente la he definido, es decir, el libre desenvolvimiento de la actividad individual. Aquellos que no tienen este fin, y que, por otra parte, no persiguen un fin de utilidad colectiva, serán contrarios a la ley de la propiedad y podrán dar lugar a una represión o a una reparación” 40 .

La propiedad es, para todo poseedor de una riqueza, el deber, la obli-

${ }^{40}$ Duguit, Las transformaciones del Derecho cit. (n. 33), p. 243. 
gación de orden subjetivo, de emplear la riqueza que posee en mantener y aumentar la interdependencia social. Esto no significa un cuestionamiento de la institución de la propiedad privada, ni del sistema económico en que se traduce. La clave en la mutación de la noción jurídica de propiedad se encuentra en que su función legitimadora no opera desde el exterior del derecho -como se venía diciendo respecto de las mentadas limitaciones-, sino que integra el contenido material del derecho. La función social no impone limitaciones al derecho de propiedad, sino que lo configura fijando sus contornos: "La propiedad no es una función social, tiene una función social".

Desde esta perspectiva, la propiedad no sólo otorga facultades sino que también "obliga". El propietario no sólo es titular de poderes, sino que también es sujeto pasivo de un haz de deberes que impone la función social. Dicho en otras palabras: el propietario tiene el deber y, por tanto, el poder de emplear la cosa que posee en la satisfacción de las necesidades individuales que le son propias, de emplear la cosa para el desarrollo de su actividad física, intelectual y moral, pero también tiene el deber y, por tanto, poder, de emplear la cosa que posee en la satisfacción de necesidades comunes o colectivas.

Esta concepción funcional de la propiedad no fue bien acogida por la doctrina de su época, pero el pensamiento de Duguit fue retomado hacia 1930 por parte de un sector de la doctrina influenciadas por el catolicismo social y el neotomismo, alcanzando una mayor audiencia y aceptación.

La consagración normativa de la función social de la propiedad aparece por primera vez en la Constitución de Weimar de 1919, en su conocido artículo 153, que después de garantizar expresamente el derecho de propiedad, añade: "La propiedad obliga. Su ejercicio debe ser al mismo tiempo un servicio prestado al bien común". Esta primera formulación constitucional de la función social de la propiedad será un hito importante en la historia de la institución, e influirá de manera decisiva en las posteriores Constituciones europeas, elaboradas tras la Segunda Guerra Mundial, que incorporarán fórmulas similares. La tendencia general que inspira este desarrollo se puede reconducir al tránsito del Estado liberal burgués al llamado Estado social de Derecho ("Sozialer Rechtsstaat"), que implica el desarrollo de la responsabilidad colectiva para la existencia social, económica y moral de los ciudadanos individuales, pero garantizando el respeto de los derechos privados.

En esta misma línea, la Constitución italiana de 1948 es la primera que retoma este camino, reconociendo y disciplinando el derecho de propiedad individual y acogiendo de forma paralela el concepto de la "función social" como objetivo de la propiedad. A este respecto el artículo 42 dispone: "La 
propiedad privada es reconocida y garantizada por la ley, que determina los modos de adquisición, de goce y los límites con la finalidad de asegurar su función social y de hacerla accesible a todos".

Por su parte la Ley Fundamental de Bonn de 1949 establece un modelo más acabado, heredero de la Constitución de Weimar, así como de su desarrollo doctrinal y jurisprudencial, que se inserta dentro del denominado orden constitucional ("Verfassungmässige Ordnung"), en el marco del Estado democrático y social de Derecho consagrado en los artículos 20.1 y 2 , y 28.1, y dentro del orden de valores establecidos en los artículos 1 y 2. De esta manera, el artículo 14 establece que: "1. Se garantizan la propiedad privada y el derecho de la herencia. 2. La propiedad obliga. Su utilización debe servir simultáneamente al bien de la comunidad".

La relativización de los derechos subjetivos en vista de la función social tendrá grandes consecuencias en la dogmática jurídico-civil, con una mayor o menor repercusión en el ámbito constitucional. En el ámbito estrictamente civil retorna con particular fuerza la doctrina del abuso del derecho en lo que se ha llamado su manifestación objetiva. Así, autores como el civilista francés Josserand afirmarán que los derechos subjetivos no son absolutos, ya que tienen un fin que les trasciende: su función social ${ }^{41}$, proponiendo como un mecanismo de corrección para modular este derecho la idea de "abuso del derecho"42. Las teorías objetivas del abuso del derecho pretendían salir de su configuración tradicional ligada al elemento intencional del animus nocendi, propia de los "actos de emulación”. De esta forma, abusa del derecho no sólo quien lo ejercita ocasionando un perjuicio a terceros, sino quien no lo ejercita de acuerdo con su fin típico ${ }^{43}$.

Detrás de estas consideraciones se encuentra la consecuencia de mayor calado que ha tenido la función social en la concepción del derecho de propiedad, pues la aceptación de que los bienes están vinculados a un determinado fin, atendiendo a su mayor trascendencia económico-social, trae consigo una ruptura del concepto unitario del derecho de propiedad. No existe un fin social común para todos los fines, sino que fines específicos que

\footnotetext{
${ }^{41}$ Josserand, Louis, Cours de Droit civil positif Français (Paris, Sirey, 1930), p. 732.

${ }^{42}$ Véase Josserand, Louis, De l'esprit des droits et de leur relativité: théorie dite de l'abus des droit (2a edición, Paris, Dalloz), 1939.

${ }^{43}$ En el mismo sentido MonTEs, Vicente, La propiedad en el sistema del Derecho civil contemporáneo (Madrid, Civitas, 1980), quien ha sostenido que: “[...] la función social y el abuso del derecho, se presentan como dos esferas, contenida la última en la primera, al propio tiempo que el abuso del derecho es una segunda fase o momento del mismo principio indicativo de la presencia del interés público o general en las actuaciones movilizadas por el interés privado”. De la misma opinión es LÓPEZ Y LÓPEZ, cit. (n. 1), pp. 1.652-1.653.
} 
determinan distintos regímenes jurídicos. Esto marcará el término de la era de "la propiedad" y el comienzo de la era de "las propiedades", que para las plumas más autorizadas no será sino un retorno a las antiguas tradiciones del período anterior a la codificación, así como una correspondencia con la realidad en el régimen jurídico de los bienes, oculta por un forzado e ideológico concepto unitario e individualista de la propiedad.

\section{El concepto unitario de propiedad y la multiplicidad de estatutos do-} minicales (la propiedad y las propiedades).

El modelo irreal del arquetipo de la propiedad absolutista, abonada por la creciente legislación especial y por la introducción del concepto de "función social" como elemento inmanente a la misma, ha dado paso a un desvanecimiento de su concepción unitaria y a una reflexión civilística moderna que se aboca a la formulación de lo que actualmente se conoce como "teoría pluralista de la propiedad". En palabras de Rodotà, esta es una de las varias aventuras intelectuales que empuja el estudio de la propiedad y que ilustra mejor las tentativas para encontrar un nuevo fundamento en la categoría, sin volver a recorrer los senderos demasiado incómodos (o desacostumbrados) de la justificación ética o de la argumentación totalmente económica ${ }^{44}$.

$\mathrm{Su}$ formulación original se atribuye a Filippo Vassalli, quien en una obra titulada "Per una definizione legislativa del diritto di proprietà" (1938) constató una realidad que ya parecía evidente, pero que la doctrina civilística no aceptaba en toda su dimensión, apegada a los cánones tradicionales en la interpretación de la relación Código Civil- leyes especiales ${ }^{45}$. Vassalli afirmó acertadamente que: "Parece corresponder al estado actual de las leyes, que han disciplinado de modo muy vario los poderes del propietario, reconocer que no hay una sola propiedad, que existen más bien propiedades, en cuanto a que el interés público es que la apropiación de los bienes comporta estatutos diversos en armonía con los propósitos perseguidos que varían bastante" 46 .

Este fenómeno ya venía siendo reconocido por autores como Josserand -que el propio Vassalli recoge en su obra-, pero que metodológicamente

${ }^{44}$ RodOtÀ, El terrible derecho, cit. (n. 18 ), p. 49.

${ }^{45}$ Vassalli, Filippo, Per una definizione legislativa del diritto di proprietà, en EL MISMO, Studi giuridici (Milano, Giuffrè, 1960), II. Sobre la obra de este autor, véase RoDotÀ, El terrible derecho, cit. (n. 20), pp. 122-126. En el mismo sentido DíEz-PICAZO, Luis, Algunas reflexiones sobre el derecho de propiedad privada en la Constitución, en AA.VV. Estudios sobre la Constitución Española. Homenaje al profesor Eduardo García de Enterría (Madrid, Civitas, 1991), II, p. 1.260.

${ }^{46}$ VASSALLI, cit. (n. 45), p. 331. 
no se desprendían de las clásicas formulaciones sujetas al concepto unitario y absolutista de la propiedad. En este sentido, Josserand después de afirmar que no hay propiedad, hay propiedades porque el interés de la sociedad exige que la apropiación de los bienes se sujete a estatutos en armonía con los fines perseguidos, que varían mucho, sostiene que: “[...] le droit de propriété est un des plus souples et des nuancés que figurent dans les différents catégories juridiques; sa plasticité est infinie" "47. Así insistía en el carácter "flexible" (souple) y de la "plasticidad" (plasticité) del derecho de propiedad, lo que con acierto ha sido calificado como muestra de la preocupación del jurista francés por no comprometer la unidad conceptual del instituto, además de que tal actitud hace pensar que se trata de un apriorismo que pesa sobre toda su formulación ${ }^{48}$.

Los antecedentes de la ruptura del concepto unitario de la propiedad hay que buscarlo en el conceptualismo jurídico alemán de fines del siglo XIX y en las visiones socializadoras francesas de principios del siglo XX. La formalización de un concepto de propiedad de naturaleza "nomológico" desplaza su "momento natural" y la coloca en manos de las corrientes positivistas, sobre todo porque el ordenamiento jurídico estaba atestado de leyes especiales y la relación con el derecho de propiedad pasó del plano de la limitación al ámbito de la configuración legal. Así, no es de extrañar que un antecedente directo de esta ruptura se encuentre en las obras de Otto von Gierke (Die soziale Aufgabe des Privatrechts) ${ }^{49}$ y de León Duguit (Les transformations générales du Droit privé depuis le Code Napoléon) ${ }^{50}$, como lo ha afirmado Rodotà ${ }^{51}$.

Sin embargo, tanto la obra de Vassalli como la de Josserand serán el punto que marcará el inicio de esta idea, como lo ha reconocido buena parte de la doctrina italiana ${ }^{52}$, aunque el principal punto de referencia ha

${ }^{47}$ Josserand, Louis, Cours de Droit civil positif Français (3a edición, París, Sirey, 1938), núm. 1517, p. 839.

${ }^{48}$ Cfr. Pugliatti, Salvatore, La proprietà nel nuovo diritto (Milano, Giuffrè, 1954), p. 148 , nota 8.

${ }^{49}$ Cfr. Gierke, cit. (n. 32).

${ }^{50}$ Duguit, Las transformaciones del Derecho cit. (n. 33).

${ }^{51}$ RodOTÀ, El terrible derecho, cit. (n. 18 ), p. 125, nota 5.

${ }^{52} \mathrm{La}$ cita es abundante en esta materia, como lo ha acreditado COLINA GAREA, Rafael, La función social de la propiedad privada en la Constitución Española de 1978 (Zaragoza, Bosch, 1997), pp. 94-97 y p. 157, nota 450. Dentro de las obras italianas que destacan, se pueden mencionar las siguientes: NATOLI, Ugo, La proprietà. Appunti delle lezioni (Milano, Giuffrè, 1965), p. 6; Constantitno, Michele, Contributo alla teoria della proprietà (Napoli, Jovene, 1967), pp. 32 ss.; AlPA, Guido - BESSONE, Mario, Poteri dei privati e statuto della proprietà (Padova, Cedam, 1980), II, p. 5556; Comporti, Marco, Ideología e norma nel diritto di proprietà, en Rivista di Diritto 
sido una famosa obra de Salvatore Pugliatti titulada: "La proprietà e le proprietà (con riguardo particolare alla proprietà terriera)" "53, quien después de una extensa exposición sobre esta materia afirma a modo de síntesis que "[...] la palabra "propiedad" no tiene hoy, si lo ha tenido alguna vez, un significado unívoco. Al contrario ella designa demasiadas cosas [...]. En cada caso el uso de ella, con las cautelas y las clarificaciones necesarias no puede ahora ya mantener la ilusión que a la unicidad del término corresponda la real unidad de un sólido y compacto instituto" ${ }^{4}$. Esta nueva y atrayente perspectiva ha llevado a autores de la autoridad de Paolo Grossi a sostener que "aquí había germinado la intuición elemental de que era hora de mirar a la relación entre el hombre y las cosas, no desde la altura del sujeto, antes bien poniéndose al nivel de las cosas y observando desde abajo aquella relación, sin preconceptos individualistas y con una disponibilidad total para leer las cosas sin gafas deformadoras. Y las cosas habían revelado que eran estructuras no genéricas sino específicas, con órdenes específicos y diversificados que requieren diversas y particulares construcciones jurídicas, si estas últimas quieren ser adecuadas y no mortificantes. De los diversos estatutos de los bienes se había llegado a la edificación de una pluralidad de propiedades, cada una de las cuales tenía un fundamento estructural basado en la recuperada realidad de los hechos naturales y económicos" 55 .

Tal como lo señala Grossi, lo importante es destacar que con esta nueva perspectiva, por primera vez después del individualismo posesorio, el individuo libre, igual, soberano, indivisible e inescindible deja de constituir el eje de la noción de propiedad, la que se intenta construir a partir de elementos objetivos y, en consecuencia, su noción es relativizada. En definitiva, se pasa de una perspectiva ex parte subiecti a una exparte re, la que ha estado siempre presente, aunque oculta durante un largo período histórico bajo el velo de las pautas interpretativas del arquetipo de propie-

Civile 30 (1984) 1, p. 311; Cantelmo, Vincenzo Ernesto, Struttura e forme della proprietà: l'aspetto agricola (Milano, Giuffrè, 1988), p. 19; COMPORTI, Marco, Considerazione sulla proprietà e sui diritti reali nella dottrina civilistica italiana dell ultimo quarantennio, en AA.VV., La Civilistica italiana dagli anni '50 ad oggi. Tra crisi dogmatica e riforme legislative (Padova, Cedam, 1991), p. 469; y RODOTÀ, Stefano, Intorno alla proprietà. Richerche, ipotesi, problemi dal dopoguerra ad oggi, en AA.VV., La Civilistica italiana dagli anni '50 ad oggi. Tra crisi dogmatica e riforme legislative (Padova, Cedam, 1991), p. 453-454. Esto es sin perjuicio de la obra capital de Salvatore Pugliatti que se cita a continuación.

${ }^{53}$ Pugliatti, Salvatore, La proprietà e le proprietà (con riguardo particolare alla proprietà terriera), en Atti del terzo congresso nazionale di diritto agrario (Milano, Giuffrè, 1954). También en Pugliatti, cit. (n. 48), pp. 145-307.

${ }^{54}$ Pugliatti , cit. (n. 48), p. 309.

${ }^{55}$ Grossi, cit. (n. 2), p. 21. 
dad absolutista constituido en instrumento fundamental para concretar y hacer realidad la ideología liberal individualista.

Esto se demuestra si se examina el pensamiento de los maestros y doctores del Derecho común, quienes no estaban sujetos a las presiones de la ideología liberal e individualista que impregnó a los códigos decimonónicos. Así, la realidad jurídica de la propiedad no era concebida por ellos a partir de un elemento unificador, como es la figura de un sujeto libre, igual y soberano, sino bajo la percepción de las utilitates rei. La singularidad de cada utilitas permite configurar toda una gama de derechos autónomos sobre la cosa, los cuales eran calificados sin mayor esfuerzo como dominia, pudiendo coexistir como plura dominia. Esta forma de concebir las situaciones jurídico reales sobre las cosas no representaba ninguna imposibilidad lógica para estos maestros y doctores, pues su concepción de la propiedad no partía de una unidad abstracta y previa que requería de un desmembramiento para justificar estas situaciones jurídicas reales. Esto no obsta a que la reunión en un solo titular de los distintos dominia diera lugar a un tipo de dominiun calificado de plenum o perfectum. Según Grossi los dominia constituyen siempre una propiedad, aunque poca tenga que compartir con la propiedad moderna, pues son una respuesta a la búsqueda de aquel momento más intenso de pertenencia, constituyendo el hilo conductor que liga el dominium clásico, los dominia de los glosadores, la propiedad de los pandectistas ${ }^{56}$. Así, el dominium y la iura in re no constituyen una antítesis lógica, como sucede en el moderno Derecho civil, sino que ambos participan de la esfera de la propiedad, al representar un poder autónomo e inmediato sobre las res corporalis ${ }^{57}$.

Además, se debe tener en consideración que el alto medioevo se caracterizó por lo que se ha llamado una "gran civilización posesoria", basado en un mundo de hechos no formal ni oficial, que crea todo un sistema de situaciones reales que se basan en la "efectividad económica sobre el bien",

${ }^{56}$ Grossi, cit. (n. 2), p. 92.

${ }^{57}$ Sin embargo, como lo señala Grossi, cit. (n. 2), p. 95, no todo ius in re puede ser elevado a dominium, sino solamente los que inciden directamente o sobre la globalidad de la cosa (como la propiedad), o sobre dimensiones particulares de la cosa (como la enfiteusis, la superficie, las concesiones prediales a largo plazo, la locación a largo plazo). Fue enseñanza recibida de los doctores del Derecho común el no elevar a dominium una servidumbre predial o una servidumbre personal, ya que éstas no podrán encerrar en el número de los iura in re aliena. En cambio, el dominium debe comprometer y acometer frontalmente el sujeto y un fragmento del cosmos, porque sólo con ellos se puede actuar un mecanismo auténticamente apropiados: hay apropiación de la cosa solamente si hay esta aproximación frontal. Enfiteusis, superficie, censo, precario, locación a largo plazo serán dominia en cuanto situaciones que comprometen la res. Dominia relativos a la utilitas rei, dominia utilia, pero dominia. 
antes que en el dominium o en los domina. "Es el reino de la efectividad [...]. No arquitecturas y formas sapientemente preconstituidas sino un germinar desordenado y vivo de situaciones toscas, no filtradas por ninguna criba cultural, que se imponen en base a hechos primordiales que son la apariencia, el ejercicio y el goce" 58 . En este sistema el centro del ordenamiento jurídico ya no lo constituye el sujeto que proyecta su poder y volición sobre las cosas, sino que las cosas en sí mismas, las que dejan de estar conculcadas por la voluntad dominadora del sujeto, transformándose en los elementos esenciales en la construcción del ordenamiento jurídico.

De esta manera, la figura jurídica del dominio útil reconduce todos estos hechos posesorios por los álveos del Derecho común, no constituyendo una diversión o un error manifiesto de interpretación de las fuentes justinianeas, sino que una gran empresa o proyecto científico que tiene el mérito de haber diseñado una institución jurídica capaz de llevar al ámbito de la validez toda esta realidad posesoria en perfecta coherencia con la mentalidad de la época.

Lo dicho permite comprender por qué para los juristas de la época no constituía una contradicción lógica hablar de dominium servitutis o de dominium ususfructus, ni configurar la confesoria in rem actio como una forma de la reivindicatoria, u otorgar la rei vindicatio al dominus utilis. $\mathrm{Y}$ esto no es sino lo que venimos sosteniendo a lo largo de este apartado y que lo expresa con toda precisión López y López al afirmar que "[...] la perspectiva de los poderes jurídicos desde "la oficina de las cosas" aboca con facilidad a una explicación pluralista de las situaciones jurídico-reales, y que esa explicación es natural para quien no parta de las tesis ideológicas del individualismo propietarios, e imposible, si se quiere partir de las mismas" 59 .

Todo este sistema se trata de romper con el triunfo de las ideas individualistas. Las premisas ideológicas liberales demandaban la construcción de un derecho de propiedad de contenido ilimitado o absoluto, que chocaba derechamente con la realidad y con la tradición doctrinal. La construcción de este concepto unitario parte necesariamente de un desmantelamiento de la propiedad dividida, en donde cobra especial relevancia la desvinculación de las cargas feudales. Por su parte, la teoría de los plura domina se pretende abandonar a partir de la integración de los iura in re en la propiedad, esto es, a partir de su construcción y definición por referencia a la propiedad. Los iura in re son algo externo a la propiedad, que desde

\footnotetext{
${ }^{58}$ Grossi, cit. (n. 2), p. 36.

${ }^{59}$ LÓPEZ y LÓPEZ, cit. (n. 1), p. 1.646.
} 
el exterior podría comprimirla y condicionar su eficacia, entendiéndola como algo preexistente y conceptualmente constante.

Sin embargo, la construcción de este nuevo arquetipo conceptual no fue el resultado exitoso de un primer intento, como ocurre habitualmente con los cambios en los núcleos o vigas de carga de una vetusta tradición y cultura. Bien se ha dicho que el legislador napoleónico era un hombre de frontera, tiene sus pies en la tierra del antiguo régimen, en donde se ha formado, mientras que tiene sus manos llenas de cosas nuevas imbuidas de la ideología liberal. ${ }^{60}$ Por eso no es de extrañar que padeciera de una disociación de pensamiento, pues frente al modelo o arquetipo de propiedad absolutista que han creado existe una gran cantidad de situaciones que limitaban la soberanía del propietario de forma impactante. De esta forma, la vieja mentalidad jurídica al alero del cual se han formado los autores intelectuales de los códigos dejó significativas desmalladuras que coexisten desarmónicamente con la nueva ideología decimonónica de la cual el Código es portador ${ }^{61}$.

Así, el trato de disfavor dado a los derechos reales limitados, por su estrecha conexión al Antiguo régimen (numerus clausus, interpretación restrictiva, carga de la prueba), estaba en contra del principio de la autonomía de la voluntad, el que sólo se limitaba a los derechos de créditos, pero no a los iura in re. Otra contradicción aparece con el reconocimiento y aceptación de todo un conjunto de limitaciones que no eran derechos reales, sino que se justificaban en los intereses de la comunidad o en las relaciones de vecindad, los que en su gran mayoría se encontraban fuera del Código, en normas especiales. Además, estas referencias genéricas que hace el Código a leyes especiales no hacen sino reconocer, desde la propia definición de propiedad, la existencia de un conjunto de limitaciones distintas a las "modificaciones" del dominio, las que por su cantidad son imposibles de codificación. A esto se debe añadir la creación de una categoría multiforme, como son las llamadas "propiedades especiales", que se han formulado para comprender en ellas diversas formas de pertenencia o de titularidades (minas, aguas, obras literarias, artísticas o científicas) que no encajan bajo el concepto de propiedad diseñado por el Código. Por último, también aparece lastrada de esta tradición el propio concepto de propiedad asumido en el Code Civil. En primer lugar, esto se nota en relación con su contenido, pues si la propiedad es el poder más amplio u omnímodo sobre las cosas, no resulta posible identificar todas las facultades que comprende

${ }^{60}$ Grossi, cit. (n. 2), p. 125.

${ }^{61}$ Prueba de ello han dado varios autores. A este respecto, véase Grossi, cit. (n. 2), p. 125-128 y, especialmente, LOPEZ y LÓPEZ, cit. (n. 1), pp. 1.646-1.648. 
sin caer en el riesgo de hacer una enumeración incompleta o voluntarista. Sin embargo, el legislador napoleónico siguió articulando el dominio en torno al ius disponendi y el ius utendi, que era fruto de la mentalidad del Derecho común, construida sobre una cultura diversa y que respondía a una visión objetiva de la pertenencia, la que parte de presupuestos antitéticos a los de los juristas del Code Civil, en donde se consideraba legítima la división del dominio. A pesar de ello, el artículo 544 del Code introduce la aporética idea de una propiedad como suma de poderes, como resultado de la adición de un gozar y de un disponer que debería haber acogido el inaceptable principio de la división de la propiedad ${ }^{62}$. En segundo lugar, si la propiedad es un poder abstracto y omnímodo, no es posible que se admitan limitaciones a la misma, lo que es totalmente contrario no sólo a la realidad sino a la propia actitud del Código, que se remite de manera general e indeterminada a un conjunto de limitaciones que se establecen o que surjan a futuro en la legislación intra y extra Codicem.

La conclusión de una estructura coherente con los requerimientos ideológicos individualistas vendrá de la mano de la Pandectística, especialmente en los trabajos de Bernhard Windscheid, que estaban apoyados en una renovada visión histórica-crítica del Derecho romano, abonada, además, por un medio social y económico que favorecía cualquier construcción jurídico-individualista. Bajo este cuño la propiedad adquiere una forma jurídica acorde con la sociedad capitalista avanzada, siendo un instrumento ágil, realista y funcional, caracterizado por su simplicidad y abstracción. La propiedad aparece como una modelación acorde con el sujeto, siendo única e inescindible, como él. Como bien lo dice Grossi "la propiedad es solamente el sujeto en acción, el sujeto a la conquista del mundo"63. La propiedad es una síntesis de poderes, que no tienen un contenido preciso y que repugna toda definición de su contenido, de forma tal que su abstracción llega a ser total. Por su parte el derecho real limitado aparece como "un accidente que puede interferir en la vida de la propiedad", operando sólo desde el exterior y proyectándose sobre su eficacia, sin posibilidad alguna de incidir en su estructura o de modificarla. Así, metodológica y conceptualmente la teoría del derecho real oscila sobre el concepto de límite de la propiedad. El derecho de propiedad es pleno, pero podía estar sujeto a límites legales y generales en razón de intereses públicos (reducidas a normas de policía o relaciones de vecindad), que van delineando su "contenido normal". Junto a estos límites están los iura in re que surgen de actos voluntarios de imposición singular y que compri-

\footnotetext{
${ }^{62}$ Cfr. Grossi, cit. (n. 2), p. 126.

${ }^{63}$ Grossi, cit. (n. 2), p. 130.
} 
mían el contenido normal del derecho de propiedad, el cual recobraba su integridad con la extinción de estos derechos, dando lugar a la extendida idea de la "elasticidad" del dominio.

Estas nociones darán lugar años más tarde a la acuñación de la ya citada terminología del conceptualismo alemán que distinguía entre "límite" ("Eigentumsbegrenzung") y "limitación" ("Eigentumsbeschränkung"), y que será uno de los elementos que llevará al retorno a la teoría de los plura dominia de la mano del positivismo jurídico y de la legislación especial.

La monolítica posición que adquirió el arquetipo de propiedad individualista comienza a desintegrarse con el crecimiento de la legislación especial. No es que la ciencia jurídica oficial del siglo XIX haya ignorado o infravalorado el significado de la legislación especial sobre la propiedad, sino que se esforzó por ofrecerle el cuadro sistemático más idóneo para su línea maestra de desarrollo ${ }^{64}$. Las alternativas eran simplemente dos: o las leyes especiales regulan sectores concretos reproduciendo el arquetipo de propiedad absolutista, siendo su aportación nula, o bien adoptaban una lógica divergente, en cuyo caso eran considerada "excepcionales" ("contra tenorem rationis iuris"), lo que impedía cualquier extensión analógica o interpretación extensiva. Además, la doctrina de la elasticidad del dominio, considerada como el resultado más eminente de la ciencia jurídica del siglo $\mathrm{XIX}^{65}$, permitió absorber de modo indoloro los golpes más duros que las nuevas leyes habían asestado al concepto de propiedad. Sin embargo, estas soluciones metodológicas tuvieron un límite insuperable frente al cambio sustancial que experimentaba el derecho de propiedad a mano de la legislación especial, revelándose insuficientes frente a un aumento cuantitativo de cargas y deberes que se imponen al propietario.

La evidente dificultad que presenta la propiedad moderna para explicar de manera adecuada la disciplina de las concretas situaciones propietarias, en cuanto constituye un modelo técnico de una ideología superada por una nueva realidad social, lleva a su relativización y desmitificación a través de la formulación de la llamada teoría pluralista de la propiedad. Ya no se habla de propiedad, sino que de las propiedades, lo que significa un cambio radical en la perspectiva de su comprensión y análisis, pues la apropiación privada se asienta en la importancia económico-social de los bienes, dejando de pivotar en un poder simple, único y homogéneo atribuido a un sujeto. Con esta nueva aportación se disuelve la vieja categoría unitaria y se deja sobrevivir el esquema de la propiedad como la

${ }^{64}$ Cfr. Rodotà, El terrible derecho, cit. (n. 18), p. 137.

${ }^{65}$ Bonfante, Pietro, Corso di Diritto romano. La proprietà (Milano, Giuffrè, 1966), II, p. 238. 
forma más intensa de pertenencia que se puede ejercer sobre los distintos bienes, atendidas su naturaleza y la función que se le asigna dentro del orden social y económico.

Todo lo dicho no significa un abandono total y absoluto del concepto unitario de propiedad, cuya influencia sigue presente no sólo en el lenguaje jurídico, sino también en el dato positivo, comenzando por la propia Constitución. El paso de la propiedad a las propiedades no ha significado la ruptura con todo el corpus dogmático construido al alero de la ideología liberal y de los códigos decimonónicos, los que ejercieron una verdadera función cuasiconstitucional. Bien lo ha sostenido Rodotà al señalar que las investigaciones tendentes a sustituir una referencia conceptual única por una multiplicidad de acepciones concretas se enfrentan a una dialéctica difícil de resolver, pues no pueden dejar en la sombra el hecho de que durante un período de tiempo suficientemente largo y representativo el "concepto abstracto" ha constituido cabalmente el punto "real" de organización de operaciones legislativas, jurisprudenciales y científicas, y no pueden renunciar tampoco a mensurar la relevancia efectiva de los singulares estatutos, en su perspectiva histórica y no sólo reconstruyendo las líneas del ordenamiento vigente ${ }^{66}$.

La doctrina italiana comenzó rápidamente a serenar el entusiasmo ante la novedosa propuesta de Pugliatti, cuya obra fue releída como un estudio que partía desde la pluralidad de propiedades para retornar a la unidad y así establecer un mínimo común denominador que permitiera reconducir las diferentes categorías a un concepto jurídico unitario. ${ }^{67} \mathrm{De}$ esta forma, varios autores arriban a la conclusión de que la pluralidad de estatutos dominicales no compromete la unidad conceptual de la propiedad privada, la que se mantendría intacta, en cuanto representa el poder más amplio que se puede ejercer sobre las $\cos ^{6}{ }^{68}$. Por lo demás, el propio Pugliatti ${ }^{69}$, así como otros autores italianos como $\mathrm{Coco}^{70}$, Ianelli ${ }^{71}$,

${ }^{66}$ RоDOTÀ, El terrible derecho, cit. (n. 18), p. 54.

${ }^{67}$ En este sentido LeONe, Guglielmo, Unità o pluralismo in tema di proprietà? en Rivista Trimestrale di Diritto e Procedura Civile 7 (1953), p. 487.

${ }^{68}$ Véase Martino, Francesco de, Comentario del Codice Civile (art. 832). Libro Terzo. Proprietà. Articoli 810-956 (4a edición, Bologna, Zanichelli, 1976), pp. 151152; y Cantelmo, cit. (n. 52), p. 19.

${ }^{69}$ Pugliatti , cit. (n. 48), p. 124.

${ }^{70}$ Coco, Giovanni Silvio, Crisi ed evoluzione nel diritto de proprietà (Milano, Giuffrè, 1965), p. 31.

${ }^{71}$ IANELLI, Antonio, La proprietà constituzionale (Napoli, Edizioni Scientifiche Italiane, 1980), pp. 269 ss. 
Tamponi $^{72}$, Perlingieri ${ }^{73}$ y Scozzafava ${ }^{74}$, insisten sobre la existencia de una disciplina común de carácter general y unitario de la propiedad, aunque no dejan de hablar de propiedades ${ }^{75}$.

Así, si bien la función social ha determinado una ruptura o fragmentación del contenido de la propiedad, sigue existiendo un contenido unitario, sin perjuicio de que varíe la extensión y el número de poderes que se le atribuyen al propietario en consideración a la trascendencia social de los bienes, lo que determina el contenido concreto del derecho. Además, no se debe olvidar que existe un doble dato positivo que viene a reafirmar esta concepción unívoca. El primero, que representa la tradición liberal y absolutista que está contenida en los códigos decimonónicos, que sigue teniendo el carácter de Derecho común o supletorio, y el segundo, representado por la moderna garantía constitucional del contenido esencial de los derechos, la que constituye una limitación importante a la acción del legislador al momento de diversificar los estatutos dominicales en consideración de la función social. Sobre este punto hemos de volver al estudiar el tema a la luz del derecho positivo vigente en España y Chile.

[Recibido el 7 y aceptado el 15 de noviembre 2008].

\section{BIBLIOGRAFÍA}

Alpa, Guido - Bessone, Mario, Poteri dei privati e statuto della proprietà (Padova, Cedam, 1980).

Baudry-Lacantinèrie, Gabriel - Cheveau, M., Traité théorique et pratique de Droit civil: Des Biens (3a edición, Paris, Sirey, 1905).

Baudry-Lacantinèrie, Gabriel, Précis de Droit civil (10ª edición, Paris, Larose, 1908).

Baudry-Lacantinèrie, Gabriel, Précis de Droit civil (Paris, Larose, 1882-1884).

Betterman, Karl August - Neumann, Franz L. - Nipperdey, Hans Carl, Die Grundrechte: Handbuch der Theorie und Praxis der Grundrechte (Berlin, Duncker \& Humblot, 1967).

Bonfante, Pietro, Corso di Diritto romano. La prorietè (Milano, Giuffrè, 1966).

BONNECASE, Julien, L'École de l'Exégèse en Droit civil: Les traits distinctifs de sa doctrine et de ses méthodes d'apres la profession de foi de ses plus illustres représentants (2a edición, París, De Boccard, 1924).

${ }^{72}$ TAmponi, Michele, Una proprietà speciale. Lo statuto dei beni forestali (Padova, Cedam, 1983), p. 304.

${ }^{73}$ Perlingieri, Pietro, Introduzione alla problematica della proprietà (Napoli, Jovene, 1971), pp. 59, 138, 150 y 153.

${ }^{74}$ Scozzafava, Oberdan Tommaso, I beni e le forme giuridiche di appartenenza (Milano, Giuffrè, 1982), pp. 185 ss.

${ }^{75}$ Sobre esta tendencia de la doctrina italiana, véase Lobato Gómez, cit. (n. 9), pp. 363-364. 
Cantelmo, Vincenzo Ernesto, Struttura e forme della proprietà: l'aspetto agrícola (Milano, Giuffrè, 1988).

Coco, Giovanni Silvio, Crisi ed evoluzione nel diritto de proprietà (Milano, Giuffrè, 1965).

Colina Garea Rafael, La función social de la propiedad privada en la Constitución Española de 1978 (Zaragoza, Bosch, 1997).

COMPORTI, Marco, Considerazione sulla proprietà e sui diritti reali nella dottrina civilistica italiana dell'ultimo quarantennio, en AA.VV., La Civilistica italiana dagli anni $` 50$ ad oggi. Tra crisi dogmatica e riforme legislative (Padova, Cedam, 1991).

Comporti, Marco, Ideología e norma nel diritto di proprietà, en Rivista di Diritto Civile 30 (1984).

ComTe, Auguste, Système de politique positive: ou traité de sociologie instituant la religion de l'humanité (Paris, 1890-1895).

Constantitno, Michele, Contributo alla teoria della proprietà (Napoli, Jovene, 1967).

De los Mozos, José Luis, El derecho de propiedad: crisis y retorno a la tradición jurídica (Madrid, Revista de Derecho Privado, 1993).

De VITA, Anna, La proprietà nell'esperienza giuridica contemporanea: analisi comparativa del Diritto francese (Milano, Giuffrè, 1969).

DíEz-PICAZO, Luis, Algunas reflexiones sobre el derecho de propiedad privada en la Constitución, en AA.VV., Estudios sobre la Constitución Española. Homenaje al profesor Eduardo García de Enterría (Madrid, Civitas, 1991), II.

Duguit, León, Las transformaciones del Derecho público y privado (traducción de A. Posada, R. Jaen y C. Posada, Buenos Aires, Heliasta, 1975).

Duguit, León, Las transformaciones generales del Derecho privado desde el Código de Napoleón (traducción de Carlos Posada, Valparaíso, Edeval, 1987).

DuguiT, León, Le droit social, le droit individuel et la transformation de l' État: conférences faites á l' École des Hautes Études Sociales (3a edición, Paris, F. Alcan, 1922).

Duguit, León, Traité de Droit constitutionnel (Paris, E. de Boccard, 1927), I.

Fernández Barreiro, A., La tradición romanística en la cultura jurídica europea (Madrid, Ramón Areces, 1992).

Gierke, Otto von, Sachenrecht, en Deutsches Privatrecht (Leipzig, Duncker \& Humblot, 1905).

Gierke, Otto, Die soziale Aufgabe des Privatrechts (Berlin, Springer, 1889).

Giner DE los Ríos, Francisco, Bases para la teoría de la propiedad (tesis doctoral, Madrid, 1867).

Giner De los Ríos, Francisco, Resumen de filosofía del Derecho (Madrid, Victoriano Suárez, 1898).

Grossi, Paolo, La propiedad y las propiedades. Un análisis histórico (traducción de Ángel López y López, Madrid, Civitas, 1992).

Hamann, Andreas. Deutsches Wirtschaftsverfassungsrecht (Neuwied, Luchterhand, 1958).

Hattenhauer, Hans, Conceptos fundamentales del Derecho civil. Introducción históricodogmática (traducción de Gonzalo Hernández, Barcelona, Ariel, 1987).

HolsteIn, Günther, Die Lehre von der öffentlich-rechtlichen Eigentumsbeschränkung (Berlin, Liebmann, 1921).

Huber, Ernst Rudolf, Wirtschaftsverwaltungsrecht (2a edición, Tübingen, Mohr, 1953). 
IANELLI, Antonio, La proprietà constituzionale (Napoli, Edizioni Scientifiche Italiane, 1980).

Ihering, Rudolf von, El fin del Derecho (Buenos Aires, Heliasta, 1978).

Josserand, Louis, Cours de Droit civil positif Français ( $3^{a}$ edición, Paris, Sirey, 1938).

Josserand, Louis, Cours de Droit civil positif Français (Paris, Sirey, 1930).

Josserand, Louis, De l'esprit des droits et de leur relativité: théorie dite de l'abus des droit (2a edición, Paris, Dalloz, 1939).

LAVEleye, Émile Louis Victor de, De la propriété et de ses formes primitives (Paris, G. Baillière et Cie., 1874).

Leone, Guglielmo, Unità o pluralismo in tema di proprietà? en Rivista Trimestrale di Diritto e Procedura Civile 7 (1953).

LÉvy, Jean Philippe, Histoire de la propriété (Paris, Presses Universitaires de France, 1972).

Lobato Gómez, J. Miguel, Propiedad privada del suelo y derecho a edificar (Madrid, Montecorvo, 1989).

LÓpez y López, Ángel, El derecho de propiedad. Una relectio, en Anuario de Derecho Civil 51 (1998) 4.

Martín Mateo, Ramón, El estatuto de la propiedad inmobiliaria, en Revista de Administración Pública 52 (1967).

Martino, Francesco de, Comentario del Codice Civile (art. 832). Libro Terzo. Proprietà. Articoli 810-956 (4a edición, Bologna, Zanichelli, 1976).

MaunZ, Theodor, Deutsches Staatsrecht (10 a edición, München, Berlin, Beck, 1961).

Menger, Anton, Über die socialen Aufgaben der Rechtswissenschaft (Wien u. Leipzig, W. Braumüller, 1895).

MONTES, Vicente, La propiedad en el sistema del Derecho civil contemporáneo (Madrid, Civitas, 1980)

Natoli, Ugo, La proprietà. Appunti delle lezioni (Milano, Guiffrè, 1965).

Parejo Alfonso, Luciano, La garantía del derecho de propiedad y la ordenación urbanistica en el Derecho alemán (I), en Revista Española de Derecho Administrativo 17 (1978).

Parejo Alfonso, Luciano, La garantía del derecho de propiedad y la ordenación urbanistica en el Derecho alemán (II), en Revista Española de Derecho Administrativo 19 (1978).

Parejo Alfonso, Luciano, La garantía del derecho de propiedad y la ordenación urbanistica en el Derecho alemán (III), en Revista Española de Derecho Administrativo 20 (1979).

Perlingieri, Pietro, Introduzione alla problematica della proprietà (Napoli, Jovene, 1971).

Peset, Mariano, Dos ensayos sobre la Historia de la propiedad de la tierra (2a edición, Madrid, Revista de Derecho Privado, 1988).

Portalis, Jean Etienne Marie, L'âme universelle de la législation, en FEnET, PierreAntoni y Ewald, Fracçis (editores), Naissance du Code civil: la raison du législateur: travaux préparatoires du Code civil. Ann VIII-an XII-1800-1804 (Paris, Flammarion, 1989).

Pugliatti, Salvatore, La proprietà nel nuovo Diritto (Milano, Giuffrè, 1954).

Pugliatti, Salvatore, La proprietà e le proprietà (con riguardo particolare alla proprietà 
terriera), en Atti del terzo congresso nazionale di diritto agrario (Milano, Giuffrè, 1954).

Reinhardt, Rudolf - Scheuner, Ulrich, Verfassungsschutz des Eigentums (Tübingen, Mohr, 1954).

Rodotà, Stefano, El terrible derecho. Estudios sobre propiedad privada (traducción de Luis Díez-Picazo, Madrid, Civitas, 1986).

RoDOTÀ, Stefano, Intorno alla proprietà. Richerche, ipotesi, problemi dal dopoguerra ad oggi, en AA.VV., La Civilistica italiana na dagli anni 50 ad oggi. Tra crisi dogmatica e riforme legislative (Padova, Cedam, 1991).

Rodotà, Stefano, Poteri dei privati e disciplina della proprietà, en El mismo Diritto privato nella societá moderna (Bologna, Zanichelli, 1982).

SCOZZAFAVA, Oberdan Tommaso, I beni e le forme giuridiche di appartenenza (Milano, Giuffrè, 1982).

TAMPONI, Michele, Una proprietà speciale. Lo statuto dei beni forestali (Padova, Cedam, 1983).

Vassalli, Filippo, Per una definizione legislativa del diritto di proprietà, en El MISMO, Studi giuridici (Milano, Giuffrè, 1960).

VIDAL, Michel, La propriété dans l'École de l'Exègése, en EL MISMO, Itinerari moderni della proprieta (Milano, Giuffrè, 1978).

VILley, Michel, Notas sobre el concepto de propiedad, en Revista de Derecho Público 35-36 (1984).

Wesenberg, Gerhard - Wesener, Gunter, Historia del Derecho privado moderno en Alemania y en Europa (Traducción de la 4a edición alemana por José Javier de los Mozos Touya, Valladolid, Lex Nova, 1998).

WIEACKER, Franz, Wandlungen der Eigentumsverfassung (Hamburg, Hanseat, 1935).

WolfF, Martín, Reichsverfassung und Eigentumm en Festgabe der Berlienr Juristischen Fakultät für Wilhelm Kahl zum Doktorjubiläum am 19. April 1923 (Tübingen, Verlag von J.C.B. Mohr, 1923). 


